\title{
COMPARISION OF FREQUENCY OF INFECTION BETWEEN INTERNAL JUGULAR AND FEMORAL VEIN DOUBLE LUMEN HEMODIALYSIS CATHETER IN CHRONIC KIDNEY DISEASE (CKD) PATIENTS
}

\author{
Saif Ullah Khan, Muhammad Amir*, Ali Javed, Shazia Nisar**, Malik Nadeem Azam Khan**, Muhammad Arsalan Javed ${ }^{* * *}$ \\ Combined Military Hospital Nowshera/National University of Medical Sciences (NUMS) Pakistan, ${ }^{*}$ Combined Military Hospital Peshawar/National University \\ of Medical Sciences (NUMS) Pakistan, ${ }^{* *}$ Pak Emirates Military Hospital/National University of Medical Sciences (NUMS) Rawalpindi Pakistan, ${ }^{* * *}$ Combined \\ Military Hospital Lahore/National University of Medical Sciences (NUMS) Pakistan
}

\section{ABSTRACT}

Objective: To compare the frequency of infection between internal jugular and femoral vein double lumen haemodialysis catheter in chronic kidney disease (CKD) patients.

Study Design: Comparative prospective study.

Place and Duration of Study: Department of Medicine, Combined Military Hospital, Peshawar, from Jan to Jun 2018. Methodology: A total of 400 patients (200 patients in each group) were included in this study. After insertion of catheter the patients were divided into 2 groups, group-A (jugular) and group-B (femoral) by lottery method and followed for development of catheter related blood stream infection (CRBI) within two weeks after its insertion.

Results: Mean age of the patients was $51.68 \pm 13.29$ and $50.89 \pm 14.31$ years in group-a and b, respectively. In group-A 193 (96.5\%) and in group-B $196(98 \%)$ patients presented with chronic kidney disease duration of $<4$ years, in group-A 7 (3.5\%) and in group-B $4(2 \%)$ patients presented with chronic kidney disease duration of $>5$ years. In both groups, $65(32.5 \%)$ were diabetic. Catheter related blood stream infection (CRBSI) was found in $13(6.5 \%)$ and 8 (14\%) in group-A \& B, respectively.

Conclusion: Infection frequently complicates double lumen catheters used for haemodialysis and infections are more frequent in patients with femoral vein catheter as compared to internal jugular vein.

Keywords: Catheter related blood stream infection, Chronic kidney disease, Femoral vein double lumen haemodialysis catheter, Internal jugular catheter.

This is an Open Access article distributed under the terms of the Creative Commons Attribution License (https://creativecommons.org/licenses/by-nc/4.0/), which permits unrestricted use, distribution, and reproduction in any medium, provided the original work is properly cited.

\section{INTRODUCTION}

Chronic kidney disease (CKD) is defined by irreversible deterioration in renal functioning as evident by decrease estimated glomerular filtration rate (eGFR) or parameters of renal dysfunction, generally established by elevated proteinuria. The severity of CKD is graded by level of eGFR ${ }^{1}$. CKD is a global health burden with prevalence between $11-13 \%$ and majority of patients in stage 3 diseases ${ }^{2}$. Epidemiology and risk factors of CKD are not extensively studied in Pakistan but diabetes mellitus (DM) and hypertension (HTN) were studied as major risk factors in urban population whereas glomerulonephritis, renal stones and CKD of unknown etiology are main factors in rural population $^{3}$. According to various studies, highest prevalence of CKD was reported to be $29.9 \%$ and lowest being $12.5 \%$ with an overall prevalence of $21.2 \%$ in Pakistani adults 4 . There are various renal replacement therapy (RRT) modalities available to CKD patients including renal transplant, peritoneal dialysis and hemodialysis,

Correspondence: Dr Saif Ullah Khan, Medical Specialist, Comibined Military Hospital, Nowshera Pakistan

Received: 28 Aug 2020; revised received: 17 Sep 2020; accepted: 21 Sep 2020 each having different features ${ }^{5}$. Haemodialysis is a basic modality of renal replacement therapy. Its efficacy and duration is dependent upon well-functioning vascular access 6 . The cornerstone of dialysis is gaining vascular access, while creating an arteriovenous fistula (AVF) remains the ultimate aim in the maintenance haemodialysis 7 . Short-term or long-term catheters are used for this purpose. Due to less stenotic and thrombotic complications, internal jugular vein is recommended as the first choice vascular access for haemodialysis ${ }^{8}$. As per recommendations, the right internal jugular vein is the first choice for vascular access followed by left internal jugular, femoral and subclavian vein respectively ${ }^{6}$. Catheters are not suited for long-term heamodialysis but in acute settings they offer number of advantages, acting as a bridge to permanent vascular access and useful for those who are ineligible for arteriovenous fistula9. There are many complications associated with centrally placed catheters but the two most common complications are catheter related blood stream infections (CRBI) and thrombosis. Occurrence of thrombosis limits utilizing vessels of arms on the side of catheterization for making arteriovenous fistulas (AVF) or grafts in future ${ }^{10}$. 
The aim of this study was to compare frequency of infection between internal jugular and femoral vein double lumen catheters in CKD pts on hemodialysis.

\section{METHODOLOGY}

It was a comparative prospective study conducted in outpatient, inpatient and emergency department of Medicine at Combine Military Hospital Peshawar, from January to June 2018. A total of 400 patients fulfilling inclusion criteria were included in study which were divided into two equal groups by lottery method. Group A patients had double lumen catheter placed in internal jugular vein while group B patients had catheter placed in femoral vein for hemodialysis. Sample size was calculated with the help of WHO calculator, level of significance was 5\%, power of test was $80 \%$, anticipated population proportion was $1.80 \%$ and anticipated population proportion was $6.94 \%$. Sampling was done by non-probability consecutive sampling. Study was approved by ethics review committee of the hospital vide certificate no A/28/DEC-2018 dated 1st December 2018. Written informed consent was taken from patients involved in the study.

CKD patients of both genders, aged 16-80 years on maintenance hemodialysis with serum creatinine of $>700 \mathrm{umol} / \mathrm{L}$, haemoglobin $>8 \mathrm{gm} / \mathrm{dl}$, serum potassium $>6.5 \mathrm{mmol} / \mathrm{L}$ were included in study. Patients having INR $>1.4$, non-catheter related infections, platelets count $<50,000$, subclavian vein catheter, age $<14$, catheters placed for non-dialysis purposes were excluded from study.

Patients fulfilling inclusion criteria were admitted in ward both from emergency and OPD, were evaluated for hemodialysis by performing, complete blood profile (for haemoglobin and platelets), renal function test/electrolytes (for creatinine and potassium), coagulation profile (for INR), chest X-ray and Urine RE (for excluding non-catheter related infections). Double lumen insertion was performed under ultrasound guidance. After insertion of catheter the patients were followed for development of catheter related blood stream infection (CRBI) by clinically evident fever of $>99^{\circ} \mathrm{F}$ and/or discharge from catheter site within two weeks after insertion of catheter. Data was analyzed in SPSS17. The mean standard deviation was calculated for quantitative variables i.e. age and duration of CKD. The frequency and percentage were calculated for qualitative variable i.e. catheter related blood stream infection, gender and DM. Comparison of infection between two groups was made by chi square test, $p$-value $\leq 0.05$ was taken as significant.

\section{RESULTS}

A total of 400 patients were divided into two groups, group-A (jugular) and group-B (femoral) by lottery method. Mean age of the patients was 51.68 \pm 13.29 and $50.89 \pm 14.31$ years in group-A and B, respectively (table-I). In group-A 148 patients $(74 \%)$ and in group-B 141 patients $(70.5 \%)$ were males while 52 patients $(26.0 \%)$ in group-A and 59 patients $(29.5 \%)$ were females (table-I). In group-A 193 (96.5\%) and in group-B 196 (98\%) patients presented with CKD duration of $<4$ years, in group-A 7 (3.5\%) and in group-B $4(2.0 \%)$ patients presented with CKD duration of $>5$ years (table-I). In both groups, 65 (32.5\%) were diabetic (table-I). Catheter related blood stream infection was found in $13(6.5 \%)$ and $28(14 \%)$ in group-A and B, respectively. Statistically significant difference was observed between two groups with $p$-value 0.013 (table-II).

Table-I: Clinical characteristics of the patients.

\begin{tabular}{|c|c|c|c|c|}
\hline Variables & \multicolumn{2}{|c|}{$\begin{array}{l}\text { Group A (Internal } \\
\text { Jugular Vein) }\end{array}$} & \multicolumn{2}{|c|}{$\begin{array}{c}\text { Group B } \\
\text { (Femoral Vein) }\end{array}$} \\
\hline \multicolumn{5}{|l|}{ Age } \\
\hline Mean \pm SD & \multicolumn{2}{|l|}{$51.68 \pm 13.29$} & \multicolumn{2}{|c|}{$50.89 \pm 14.31$} \\
\hline \multicolumn{5}{|l|}{ Gender } \\
\hline Male & \multirow{2}{*}{\multicolumn{2}{|c|}{$\begin{array}{c}148(74 \%) \\
52(26 \%)\end{array}$}} & \multirow{2}{*}{\multicolumn{2}{|c|}{$\begin{array}{c}141(70.5 \%) \\
59(29.5 \%)\end{array}$}} \\
\hline Female & & & & \\
\hline \multicolumn{5}{|c|}{ Duration of Chronic Kidney Disease } \\
\hline$\leq 4$ Years & \multicolumn{2}{|c|}{$193(96.5 \%)$} & \multicolumn{2}{|c|}{$196(98 \%)$} \\
\hline$\geq 5$ Years & \multicolumn{2}{|l|}{$7(3.5 \%)$} & \multicolumn{2}{|c|}{$4(2 \%)$} \\
\hline Mean \pm SD & \multicolumn{2}{|l|}{$2.07 \pm 1.7$} & \multicolumn{2}{|c|}{$2.04 \pm 1.08$} \\
\hline \multicolumn{5}{|c|}{ Diabetes Mellitus } \\
\hline Yes & \multirow{2}{*}{\multicolumn{2}{|c|}{$\begin{array}{c}65(32.5 \%) \\
135(675 \%)\end{array}$}} & \multicolumn{2}{|c|}{$65(32.5 \%)$} \\
\hline No & & $135(67.5 \%)$ & \multicolumn{2}{|c|}{$135(67.5 \%)$} \\
\hline \multicolumn{5}{|c|}{ Table-II: Catheter related blood stream infection. } \\
\hline \multirow{4}{*}{$\begin{array}{l}\text { Catheter } \\
\text { Related } \\
\text { Blood Stream } \\
\text { Infections }\end{array}$} & \multirow{4}{*}{$\begin{array}{l}\text { Group A } \\
\text { (Internal } \\
\text { Jugular } \\
\text { Catheter) }\end{array}$} & \multicolumn{2}{|c|}{ Group B } & \multirow{4}{*}{$\begin{array}{c}p- \\
\text { value }\end{array}$} \\
\hline & & & Femoral & \\
\hline & & \multirow{2}{*}{\multicolumn{2}{|c|}{$\begin{array}{l}\text { Vein } \\
\text { Catheter) }\end{array}$}} & \\
\hline & & & & \\
\hline Yes & $13(6.5 \%)$ & \multicolumn{2}{|c|}{$28(14 \%)$} & \multirow{2}{*}{0.013} \\
\hline No & $187(93.5 \%)$ & \multicolumn{2}{|c|}{$172(86 \%)$} & \\
\hline
\end{tabular}

\section{DISCUSSION}

Blood stream infection or bacteremia is most common complication noted after insertion of double lumen cathter (DLC) and studies conducted in Turkey and Netherlands concluded that the complication of bacteremia or blood stream infection after double lumen catheter insertion reached up to $22 \%$ and $23.9 \%$ respectively ${ }^{11}$. Study conducted at Jinnah Postgraduate Medical Centre Karachi by Ali et al reported that 14.7\% patients developed catheter related infections ${ }^{12}$. Various types of infections including exit site infections, localized infections, blood stream infections and poc- 
ket infections can occur due to double lumen catheters. There is almost 10 folds increased risk of bcteremia with catheters as compared to arteriovenous (AV) fistulas ${ }^{13}$.

History of bacteremia and bacteruria, previous catheter related infection, MRSA carriage in previous 3 months before implantation of catheter were identified as prominent risk factors for CRBSI in study conducted by Delistefani et al ${ }^{14}$. Duration of catheter insertion was also determined as infection risk factor in a study and risk of infection increases after 2 weeks of insertion so these must be removed and replaced at different site within 2 weeks to prevent infections ${ }^{15}$. Catheter insertion site is also important determinant of infection and femoral vein is associated with higher infection and thrombosis rate as compared to subclavian vein ${ }^{16}$.

Study conducted in 2018 revealed 51\% of catheters had microbiological colonization, catheter related bloodstream infection was found in $14.3 \%$ of patients and catheter insertion site infection was observed in $10.4 \%$ patients. Results of our study are in congruence with study conducted by Viviane Ferriera which concluded that $32.9 \%$ cases with femoral vein catheters developed bloodstream infections in comparison to $18.75 \%$ patients with jugular vein catheters ${ }^{17}$. Another study concluded that there is remarkably lower risk of infections in internal jugular vein catheterization $(22.2 \%)$ in comparison to femoral $(33.3 \%)^{18}$. Catheter related bloodstream infections can be reduced by using ethanol locks and strictly adhering to insertion and maintenance bundles and usage of single lumens when appropriate ${ }^{19}$.

\section{Funding Source}

All patients were entitled for free treatment at CMH Peshawar and funded by hospital.

\section{ACKNOWLEDGEMENT}

We are thankful to all the consultants at department of medicine and nursing staff of haemodialysis unit in particular at $\mathrm{CMH}$ Peshawar.

\section{CONCLUSION}

Infection frequently complicates double lumen catheters used for haemodialysis. Although double lumen catheters provide satisfactory means for haemodialysis, they are frequently complicated by infections and infections are higher in femoral vein double lumen catheters as compared to internal jugular vein catheters.

\section{CONFLICT OF INTEREST}

This study has no conflict of interest to be declared by any author.

\section{REFERENCES}

1. Linker LA, Tonelli M, Hemmelgarn BR, Levitan EB, Munter P. Comparison of concurrent complication of CKD by 2 risk categorization systems. Am J Kidney Dis 2012; 59(3): 372-81.

2. Hill NR, Fatoba ST, Oke JL, Hirst JA, Callaghan CA, , Lasserson DS, et al. Global Prevalence of Chronic Kidney Disease-A Systematic Review and Meta-Analysis. PLoS One 2016; 11(7): 1-18.

3. Imtiaz S, Salman B, Qureshi R, Drohlia MF, Ahmad A. A review of the epidemiology of chronic kidney disease in pakistan: a global and regional perspective. Saudi J Kidney Dis Transpl 2018; 29(6): 1441-51.

4. Hasan M, Sutradhar I, Gupta RD, Sarker M. Prevalence of chronic kidney disease in South Asia: a systematic review. BMC Nephrol 2018; 19(1): 291-95.

5. Purnell TS, Auguste P, Crews DC, Lamprea-Montealegre J, Olufade T, Greer R, et al. Comparison of life particaption activities among adults treated by haemodialysis, peritoneal dialysis and kidney transplantation: a systemic review. Am J Kidney Dis 2013; 62(5): 953-73.

6. Les J,Wankowila Z. Methods of central vascular access for haemodialysis. Anaesthesiol Intensive Ther 2013; 45(3): 171-76.

7. Sampathkumar K, Ramakrishnan M, Sah AK, Sooraj Y, Mahaldhar A, A Jeshkumar R. Tunneled central venous catheters: Experience from a single centre. lnd J Nephrol 2011; 21(2): 107-11.

8. Karkee DV. Subclavian vein dialysis access catheter-complications are low. Nepal Med Coll J 2010; 12(4): 248-52.

9. Besarab A. Catheter management in hemodialysis: delivering adequate flow. Clin J Am Soc Nephrol 2011; 6(1): 227-34.

10. Naroienejad M, Saedi D, Rezvani A. Prevelance of central vein stenosis following catheterization in patients with end stage renal disease. Saudi J Kidney Dis Transpl 2010; 21(5): 975-78.

11. Basri NS, Patrianef. Infection of double lumen catheter as hemodialysis access. New Ropan J Surg 2017; 2(1): 25-28.

12. Ali M, Das B, Kumar S, Memon R, Dayu B, Babeeta. Catheter related infection in hemodialysis patients with double lumen catheter. Professional Med J 2019; 26(8): 1278-82.

13. Wilcox TA. Catheter-Related Bloodstream Infections. Semin Interv Radiol 2009; 26(2): 139-43.

14. Delistefani F, Wallbach M, Müller GA, Koziolek MJ, Grupp C. Risk factors for catheter-related infections in patients receiving permanent dialysis catheter. BMC Nephrol 2019; 20(1): 199-204.

15. Qureshi AL, Abid K. Frequency of catheter related infections in haemodialysed Uraemic patients. J Pak Med Assoc 2010; 60(8): 671-75.

16. Patel AR, Patel AR, Singh S, Singh S, Khawaja I. Central line catheters and associated complications: a review. Cureus 2019; 11(5): e4717-20.

17. Ferreira V, Neto MM, Cardeal da Costa JA. Association of infections with the use of a temporary double-lumen catheter for hemodialysis. Nephrol Nursing J 2018; 45(3): 261-67.

18. Parameswaran R, Sherchan JB, Varma DM, Mukhopadhyay C, Vidyasagar S. Intravascular catheter-related infections in an Indian tertiary care hospital. J Infect Dev Ctries 2011; 5(6): 452-58.

19. Duesing LA, Fawley JA, Wagner AJ. Central venous access in the pediatric population with emphasis on complications and prevention strategies. Nutr Clin Pract 2016; 31(4): 490-501. 